\title{
Outcome Comparison of Different Reconstructive Approaches for Axillary Defects Secondary to Radical Excision of Hidradenitis Suppurativa
}

\author{
Vlad Tereshenko a, b Riccardo Schweizer ${ }^{a} \quad$ Matthias Waldner ${ }^{a} \quad$ Bong-Sung Kim ${ }^{a}$ \\ Pietro Giovanolia Holger Jan Klein ${ }^{c, d}$
}

${ }^{a}$ Department of Plastic Surgery and Hand Surgery, University Hospital Zurich, Zurich, Switzerland; ${ }^{\mathrm{b} C l i n i c a l}$ Laboratory for Bionic Extremity Reconstruction, Department of Plastic, Reconstructive and Aesthetic Surgery, Medical University of Vienna, Vienna, Austria; 'Department of Plastic Surgery and Hand Surgery, Kantonsspital Aarau, Aarau, Switzerland; dUniversity of Zurich, Zurich, Switzerland

\section{Keywords}

Hidradenitis suppurativa $\cdot$ Axillary defect $\cdot$ Axillary reconstruction · Split-thickness skin graft · Posterior arm flap

\begin{abstract}
Background: Radical excision of debilitating hidradenitis suppurativa lesions is the only curative approach in the advanced stages of the disease. Different concepts for axillary reconstruction do exist, but data on their clinical outcome are scarce. Methods: This is a retrospective cohort study of two reconstructive methods (posterior arm flap vs. vacuumassisted closure [VAC] + split-thickness skin graft [STSG]) for axillary defects in patients with severe axillary hidradenitis suppurativa treated at the University Hospital Zurich between 2005 and 2020. Results: A total of 35 patients (mean age $36 \pm 10$ years, mean BMI $29 \pm 5 \mathrm{~kg} / \mathrm{m}^{2}$, Hurley stage II-III) with 67 operated axillae were stratified according to their type of reconstruction. Median operation time in the flap group was 144 min (IQR 114-207) (cumulative 181 min [IQR 124-300]) and $50 \mathrm{~min}$ (IQR 40-81) in the VAC + STSG group (cumulative $151 \mathrm{~min}$ [IQR 94-194], $p<0.01 ; p=0.20$ [cumulative time]). The cumulative length of stay was $6 \pm 3$ days in the flap group and $14 \pm 7$ days in the VAC + STSG group $(p<$
\end{abstract}

karger@karger.com www.karger.com/drm

Karger $\stackrel{\text { ' }}{5}$

GOPEN ACCESS
(C) 2022 The Author(s)

Published by S. Karger AG, Basel

This is an Open Access article licensed under the Creative Commons Attribution-NonCommercial-4.0 International License (CC BY-NC) (http://www.karger.com/Services/OpenAccessLicense), applicable to the online version of the article only. Usage and distribution for commercial purposes requires written permission.
0.01). Time to complete wound healing was 27 days (IQR 20 49 ) in the flap group and 62 days (IQR 41-75) in the VAC + STSG group $(p<0.01)$. Vancouver Scar Scale score was 6 (IQR 4-9) in the flap group and 11 (IQR 9-12) in the VAC + STSG group $(p<0.01)$. Protective sensory recovery was most satisfactory in the flap group $(p<0.01)$. Forty-four percent of patients of the VAC + STSG group demonstrated functional impairment of arm abduction. Time to return to work was less in group A with 42 days (IQR 27-57) needed as compared to group B with 48 days (IQR 34-55) needed ( $p=0.32$ ). The average cost saving was $25 \%$ higher for the flap group than for the VAC + STSG group. Conclusion: Despite an increased operation time, axillary reconstruction by the posterior arm flap yields a reduced length of stay, less time to complete wound healing along with restoration of a protective sensibility, and less axillary scarring avoiding functional deficits - eventually allowing earlier return to work. @ 2022 The Author(s).

Published by S. Karger AG, Basel

\section{Introduction}

Hidradenitis suppurativa (HS) is a wearing chronic inflammatory disease, which affects the terminal hair follicles in intertriginous skin areas $[1,2]$. In advanced stages,
Correspondence to:

Holger Jan Klein, holger.klein@ksa.ch 
affected patients develop profound abscesses with fistula formation, leading to severe quality of life impairment [3]. In spite of its high global prevalence $(0.05-4.1 \%)$, many patients are still not treated adequately [4].

To date, available therapeutic approaches are limited and most of them are solely symptom-related without curative intention. Major factors affecting therapeutic decision-making for $\mathrm{HS}$ are the localization and extent of the disease [5]. Basically, the therapeutic spectrum encompasses conservative measures, such as lifestyle modification, local or systemic antimicrobial therapy, and administration of monoclonal antibodies (e.g., adalimumab) [5]. Advanced stages of HS usually require surgery. Based on the European S1 guideline and HS ALLIANCE working group, the radical resection of wide-spread lesions with removal of all hair-bearing skin and affected subcutaneous tissue is recommended for a recurrence-free outcome [6-8]. Subsequent coverage of the defects may be realized by primary/secondary wound closure as well as by reconstructive approaches using skin grafts or various flap surgeries $[9,10]$.

The axilla is one of the regions most frequently affected by HS. The radical excision leaves large defects that require thorough reconstruction in order to avoid functional and aesthetic long-term sequelae. To date, there is no conclusive data regarding perioperative factors and subsequent clinical outcome after different reconstructive approaches of such axillary defects $[10,11]$. Against this background, we set out to compare the following two reconstructive procedures with regard to their clinical outcome, procedure-related factors, and financial expenditure: (A) coverage by the neurovascular-pedicled posterior arm flap [12] and (B) vacuum-assisted closure (VAC) with subsequent split-thickness skin grafting (STSG).

\section{Materials and Methods}

\section{Patients}

Medical records of patients diagnosed with HS who underwent surgical treatment at the Department of Plastic Surgery and Hand Surgery at the University Hospital Zurich between 2005 and 2021 were identified. Inclusion criteria were age $>16$ years, axillary HS at Hurley stage II or III diagnosed by an independent dermatologist, and radical resection of all hair-bearing skin of the axilla. In patients with bilateral axillary HS, both axillae were operated within one surgery. Patient-specific demographic data included sex, date of birth, age at the first surgical procedure, disease-associated comorbidities, smoking habit, and body mass index (BMI). Patients $(n=38)$ were stratified according to the reconstructive approach into two groups: group A $(n=8,15$ axillae) treated with the posterior arm flap and group $\mathrm{B}(n=27,52$ axillae $)$ treated with
VAC and STSG (Fig. 1). All data was collected retrospectively by a single person (V.T.) and analyzed in a pseudonymized manner. Approval was obtained from the Ethics Committee of Zurich (BASEC-No.: 2020-01135).

\section{Outcome Parameters}

Data on the surgical treatment included the number of surgical procedures (primary radical excision, multiple regrafting surgeries as well as changes of VAC dressings) until complete wound closure, operation time, and complications and their grade according to Clavien-Dindo (I-V) [13]. Data on the postoperative course encompassed time to complete wound healing, cumulative time of in-patient stay, number of out-patient claims, and duration of sick leave. Complete wound healing was defined as either fully epithelialized area after STSG or flap healing without dehiscence and stable conditions. Sick leave was defined as a period of time after discharge from the hospital, where patients were not able to work due to postoperative wound management. Data on the clinical outcome comprised number of recurrences (perifocal recurrence in the same axilla), scar quality using the Vancouver Scar Scale (VSS [0-13]) [14], sensory recovery using the Mackinnon-Dellon scale (S0-S4) [15], and presence of any functional impairment using range of motion for arm abduction. Outcome parameters (recurrence, VSS, and sensory recovery) were assessed per reconstructed axilla. Functional outcome (range of motion) was evaluated during bilateral arm abduction for both sides and stratified into one of four groups: $180^{\circ} ; 150^{\circ}-180^{\circ} ; 100^{\circ}-150^{\circ}$; or $<100^{\circ}$.

\section{Cost Analysis}

Costs were defined as total direct costs of patient care, allocated to each case under the REKOLE (Bern, Switzerland) full cost accounting method [16]. REKOLE is the Swiss national cost accounting system for hospitals. National legislation demanded comparability and transparency in hospital cost accounting, which is why REKOLE was introduced. It is a full cost accounting method with the hospital case being the cost unit, which means that all costs including overheads are allocated to the treated patients. The case earnings were calculated by subtracting the case costs from the calculated case revenue. The accuracy of revenue-determining coding as well as cost data in Switzerland is continuously subject to external and independent audits. For the present study, overall costs as well as costs after the reimbursement per patient were evaluated. The average cost saving (ACS) was calculated as ratio of the average costs' difference between the flap (ACF) and VAC + STSG (ACVS) groups to the average cost in the VAC + STSG group (ACVS): $[A C S=(A C V S-A C F) / A C V S]$. Costs are presented as absolute values in US dollar (USD).

\section{Statistical Analysis}

Data were analyzed using GraphPad Prism 8.0.2 (GraphPad Software, San Diego, CA, USA). Parametric values are expressed as mean with standard deviation (SD) and nonparametric values are expressed as median with interquartile range (IQR). To check normal distribution of the variables, the Kolmogorov-Smirnov test was used (online suppl. Table S1; for all online suppl. material, see www.karger.com/doi/10.1159/000521573). Fisher's exact test was applied for comparison of nominal variables (gender, smoking status). Mann-Whitney U test was applied to compare nonparametric metric and ordinal variables (time between diagnosis and first surgical procedure, operation time for the primary excision, cumula- 
Fig. 1. Schematic illustration of the two reconstructive modalities for axillary defects. a Reconstruction with the posterior arm flap. b Wound conditioning with VAC and subsequent STSG.

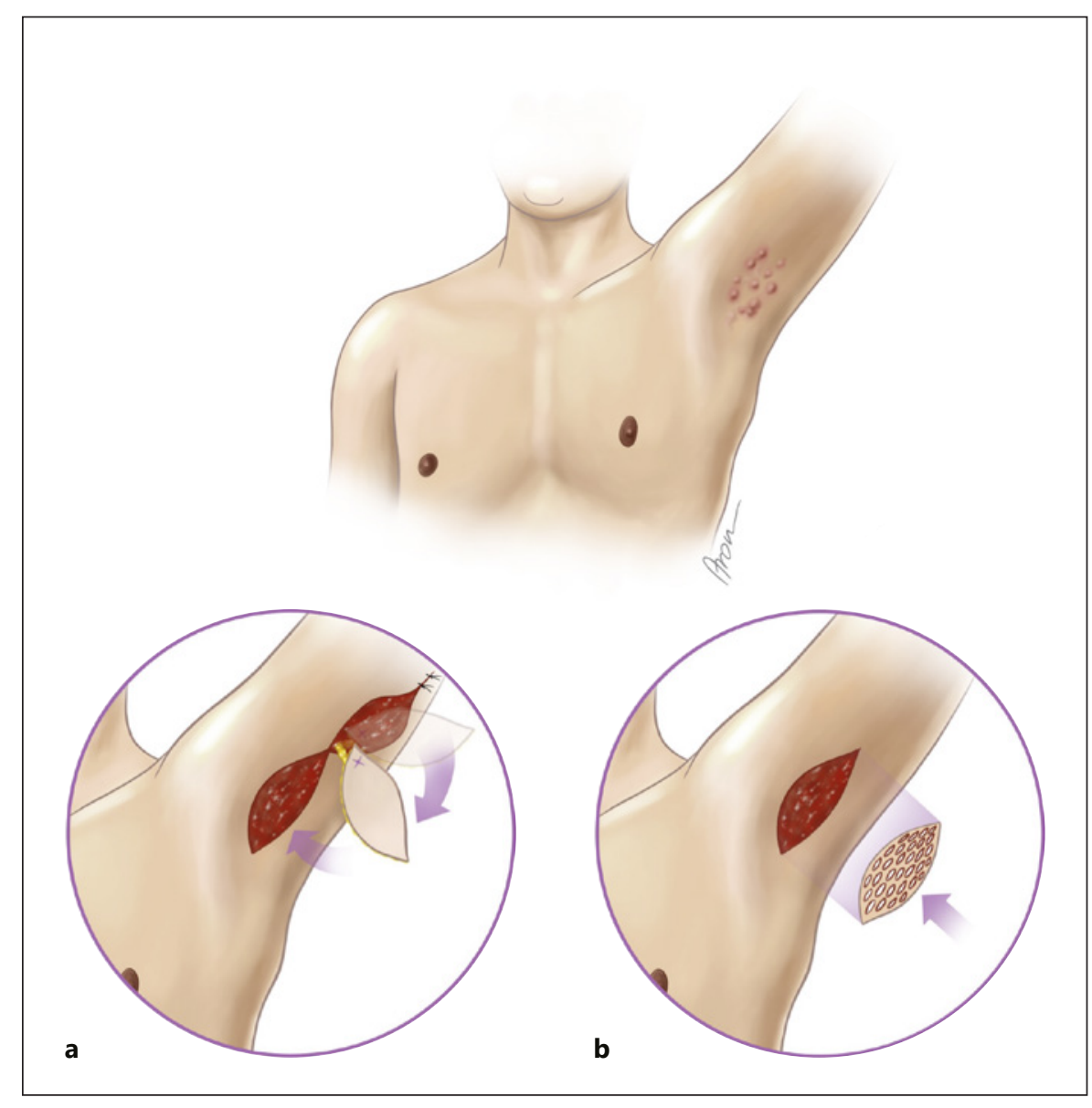

tive operation time, time to complete wound healing, and duration of sick leave as well as overall costs per patient; number of surgical procedures, out-patient claims, VSS, and sensory recovery score). Unpaired $t$ test was applied to compare normally distributed metric variables (age, BMI, cumulative in-patient stay, and cost coverage). All tests were two-tailed, $p<0.05$ was considered significant.

\section{Results}

\section{Baseline Characteristics}

A total of 35 patients (67 axillae) were included in this study (Table 1). Mean age at surgery was 36.3 years (range $16-50$ ) in group A and 36.6 years (range 18-51) in group $\mathrm{B}(p=0.96)$. Most patients were male: $75 \%$ in group $\mathrm{A}$ and $55.6 \%$ in group $B(p=0.43)$. The majority of patients suffered from obesity (6 [75\%] in group A and 18 [66.7\%] in group B): $33.4 \pm 5.0 \mathrm{~kg} / \mathrm{m}^{2} \mathrm{BMI}$ in group A and $28.3 \pm 5.3$ $\mathrm{kg} / \mathrm{m}^{2}$ in group $\mathrm{B}(p=0.48)$. Most of the patients were current smokers: $50 \%$ in group A and $88.9 \%$ in group B $(p=0.03)$. Most patients were diagnosed with Hurley stage III: 6 (75\%) in group A and $26(96.3 \%)$ in group B.
Mean duration between the diagnosis of HS and the first consultation regarding the surgical treatment was 4.0 years (IQR 3.0-13.5) for group A and 5.0 years (2.8-10.5) for group B $(p=0.86)$.

\section{Surgery-Related Outcome}

A total of 67 axillary reconstructions were evaluated (Table 2). Duration of the first surgical procedure (i.e., excision $+/$ - reconstruction) differed significantly between the two groups: $143.5 \mathrm{~min}$ (IQR 113.5-206.5) in group A and 50.0 min (IQR 40.0-81.3) in group B ( $p<$ 0.01 ). The cumulative time including all surgical procedures from primary excision to coverage of the axillary defects did not differ significantly between group A (181.0 min [IQR 124.3-299.8]) and group B (150.5 min [IQR 93.8-193.8]; $p=0.20)$. The average number of surgical procedures needed for complete healing of the axillary defect was significantly higher in group B with 3.0 (IQR 2.0-4.0) as opposed to group A with 2.0 (IQR 1.3-2.8) ( $p$ $=0.02$ ). The cumulative in-patient stay differed significantly between the two groups: $6.1 \pm 2.9$ days in group A 
Table 1. Baseline characteristics of 35 patients according to the two types of reconstruction

\begin{tabular}{|c|c|c|c|}
\hline & $\begin{array}{l}\text { Group A, } \\
\text { flap surgery } \\
(n=8)\end{array}$ & $\begin{array}{l}\text { Group B, } \\
\text { VAC + STSG } \\
(n=27)\end{array}$ & $p$ value \\
\hline \multicolumn{4}{|l|}{ Gender, $n(\%)$} \\
\hline Male & $6(75)$ & $15(55.6)$ & \multirow[t]{2}{*}{0.43} \\
\hline Female & $2(25)$ & $12(44.4)$ & \\
\hline Age, mean (range), years & $36.3(16-50)$ & $36.6(18-51)$ & 0.96 \\
\hline $\mathrm{BMI}$, mean $\pm \mathrm{SD}, \mathrm{kg} / \mathrm{m}^{2}$ & $33.4 \pm 5.0$ & $28.3 \pm 5.3$ & \multirow[t]{4}{*}{0.05} \\
\hline Normal weight (BMI $\leq 25), n(\%)$ & 0 & $6(22.2)$ & \\
\hline Overweight (BMI 25-30), n (\%) & $2(25)$ & $3(11.1)$ & \\
\hline Obesity (BMI >30), $n(\%)$ & $6(75)$ & $18(66.7)$ & \\
\hline \multicolumn{3}{|l|}{ Smoking, $n(\%)$} & \multirow[t]{4}{*}{0.03} \\
\hline Current smoker & $4(50.0)$ & $24(88.9)$ & \\
\hline Nonsmoker & $3(37.5)$ & $1(3.7)$ & \\
\hline Ex-smoker & $1(12.5)$ & $2(7.4)$ & \\
\hline \multicolumn{3}{|l|}{ Comorbidities, $n$} & \multirow[t]{5}{*}{-} \\
\hline Crohn's disease & 1 & 0 & \\
\hline Diabetes mellitus & 2 & 4 & \\
\hline PCOS & 2 & 0 & \\
\hline Bronchial asthma & 0 & 3 & \\
\hline \multicolumn{3}{|l|}{ Hurley, $n(\%)$} & \multirow[t]{3}{*}{-} \\
\hline Stage II & $2(25.0)$ & $1(3.7)$ & \\
\hline Stage III & $6(75.0)$ & $26(96.3)$ & \\
\hline \multicolumn{4}{|c|}{ Time between diagnosis and first surgical } \\
\hline
\end{tabular}

Table 2. Surgical data for two different approaches for axillary reconstruction

\begin{tabular}{|c|c|c|c|}
\hline Operation time for the primary excision, median (IQR), min & $143.5(113.5-206.5)$ & $50.0(40.0-81.3)$ & $<0.01$ \\
\hline Cumulative operation time, median (IQR), min & $181.0(124.3-299.8)$ & $150.5(93.8-193.8)$ & 0.20 \\
\hline Number of surgical procedures, median (IQR) & $2.0(1.3-2.8)$ & $3.0(2.0-4.0)$ & 0.02 \\
\hline Cumulative in-patient stay, mean $\pm \mathrm{SD}$, days & $6.1 \pm 2.9$ & $13.8 \pm 6.6$ & $<0.01$ \\
\hline None & $12(80)$ & 45 (86.5) & \\
\hline Secondary hemorrhage & $1(6.7)$ & $7(13.5)$ & \\
\hline Venous congestion & $1(6.7)$ & $\mathrm{n} / \mathrm{a}$ & \\
\hline Flap loss & $1(6.7)$ & $\mathrm{n} / \mathrm{a}$ & \\
\hline
\end{tabular}

Bold values indicate statistical significance. ${ }^{1}$ Complications were calculated per axilla and not per patient with a total of $n=15$ in group A and $n=52$ in group B.

and $13.8 \pm 6.6$ days in group B $(p<0.01)$. All surgery-related postoperative complications were of grade II (Clavien-Dindo classification) and comprised (per axilla) hemorrhage in $1 / 15(6.7 \%)$ and $7 / 52(13.5 \%)$ in groups $\mathrm{A}$ and $\mathrm{B}$, respectively. Additionally, in group A, flap surgery-related complications were reported: venous con- gestion of 1 flap (6.7\%) and 1 flap loss (6.7\%). The number of out-patient claims did not differ significantly between the two groups (group B: 6.5 appointments [IQR $4.0-9.0$ ] vs. group A: 4.5 appointments [IQR 3.0-7.5]; $p$ $=0.19$ ). 
Table 3. Clinical outcome for different reconstruction modalities of the axilla

\begin{tabular}{|c|c|c|c|}
\hline Vancouver Scar Scale score (0-13), median (IQR) & $6.0(4.0-8.8)$ & $11.0(9.0-12.0)$ & $<0.01$ \\
\hline Arm abduction $\mathrm{ROM}, n(\%)$ & & & - \\
\hline $180^{\circ}$ & $8(100)$ & $15(55.6)$ & \\
\hline $100^{\circ}-150^{\circ}$ & 0 & $4(14.8)$ & \\
\hline$<100^{\circ}$ & 0 & $5(18.5)$ & \\
\hline Sensory recovery score (S0-S4), median (IQR) & $3.0(2.3-4.0)$ & $2.0(1.0-2.0)$ & $<0.01$ \\
\hline Time to complete wound healing, median (IQR), days & $27.0(20.0-49.0)$ & $62.0(40.8-74.5)$ & $<0.01$ \\
\hline Duration of sick leave from the first surgery, median (IQR), days & $42.0(27.0-57.0)$ & $48.0(34.5-55.5)$ & 0.32 \\
\hline
\end{tabular}

Bold values indicate statistical significance. ROM, range of motion. ${ }^{1}$ The percentage of recurrences was evaluated per axilla with a total of $n=52$ in group $B$.

Table 4. Cost analysis

\begin{tabular}{llll}
\hline & $\begin{array}{l}\text { Group A, flap surgery } \\
(n=6)\end{array}$ & $\begin{array}{l}\text { Group B, VAC + STSG } \\
(n=14)\end{array}$ & $\begin{array}{l}p \\
\text { value }\end{array}$ \\
\hline $\begin{array}{l}\text { Average costs, median (IQR), USD } \\
\text { Average cost coverage by the hospital, mean } \pm \text { SD, USD }\end{array}$ & $\begin{array}{l}20,183(16,197-30,391) \\
-3,683 \pm 2,836\end{array}$ & $22,061(16,625-31,306)$ & 0.90 \\
\hline
\end{tabular}

Average overall costs were calculated per patient in both groups. After the reimbursement for the complete treatment, average cost coverage was assessed per patient. USD, US dollar.

\section{Clinical Outcome}

Table 3 summarizes the postoperative clinical results. Recurrence of HS was reported in 5 patients (9.6\%) in group B. Group A (Fig. 2) scored lowest on the postoperative VSS with 6.0 (IQR 4.0-8.8) and differed significantly from group B with 11.0 (IQR 9.0-12.0) $(p<0.01$ ). When assessing sensory recovery with the posterior arm flap, group A achieved better results on the MackinnonDellon scale (S0-S4): group A, 3.0 (IQR 2.3-4.0) and group B, 2.0 (IQR 1.0-2.0) $(p<0.01)$. No functional impairment in terms of reduced arm abduction was observed in group A, whereas 12 patients (44.4\%) of group $B$ showed reduced arm abduction. Time to complete wound healing was significantly shorter in group A with 27.0 days (IQR 20.0-49.0) as compared to group B with 62.0 days (IQR 40.8-74.5) $(p<0.01)$ (Fig. 3). Consequently, patients of group A with 42.0 days (IQR 27.0-57.0) needed less time to return to work than patients of group B with 48.0 days (IQR 34.5-55.5) $(p=0.32$ ).

Reconstruction of Axillary Defects after Excision of HS

\section{Cost Analysis}

Average overall costs per patient were similar in group A (USD 20,183 [IQR 16,197-30,391]) and group B (USD 22,061 [IQR 16,625-31,306]; $p=0.90$ ). The average overall cost saving for the posterior arm flap procedure was USD 6,943 (25.3\%). The average cost coverage after the reimbursement for the complete treatment was similar for the posterior arm flap and the VAC + STSG groups: $-3,683 \pm 2,836$ versus $-5,916 \pm 10,712(p=0.48)(\mathrm{Ta}-$ ble 4$)$.

\section{Discussion}

The treatment of HS remains a challenging interdisciplinary task. Despite various conservative therapeutic options, the radical surgical approach is considered most effective in advanced stages of the disease [7, 8, 17, 18]. Nevertheless, there is no evidence-based consensus re- 


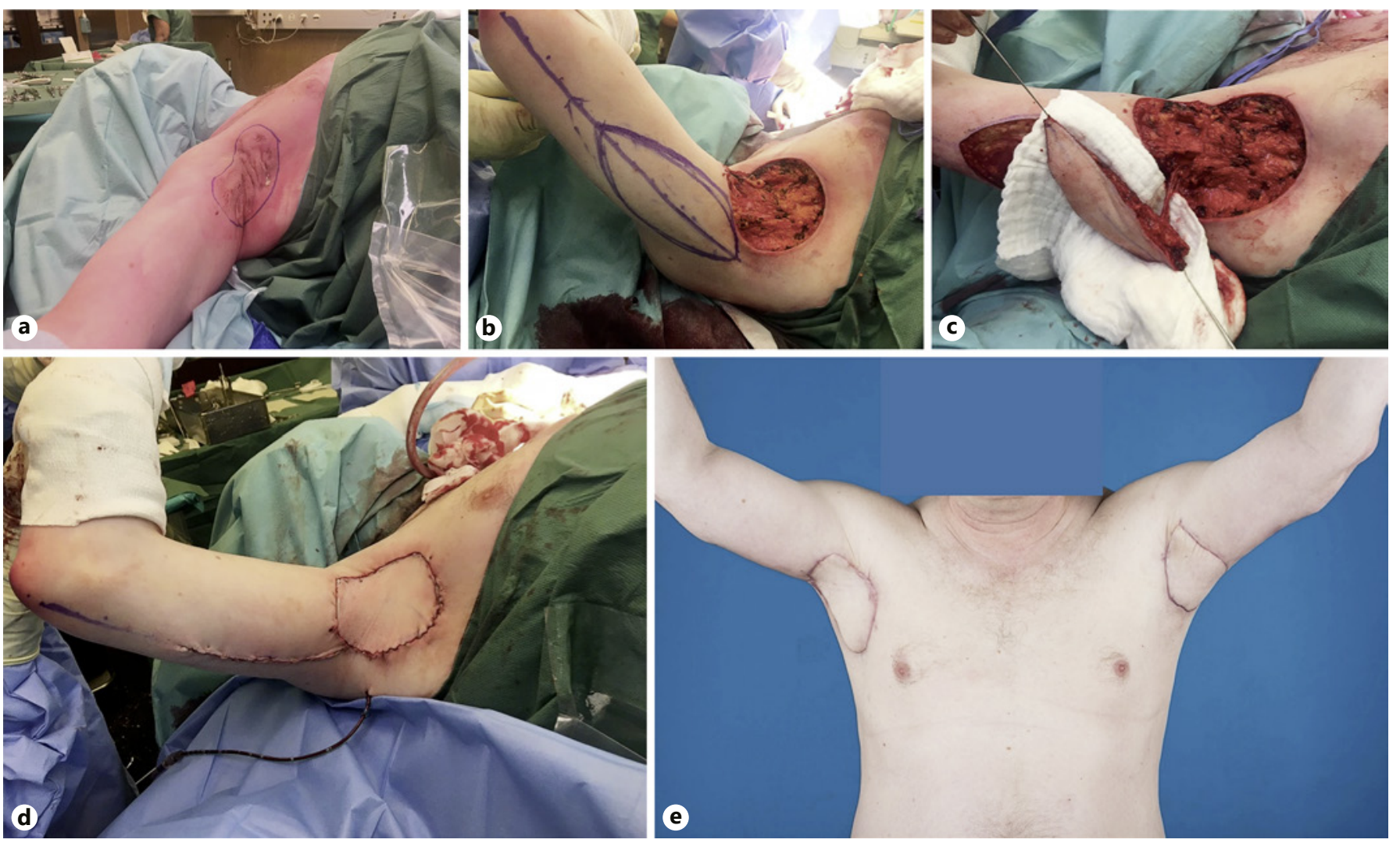

Fig. 2. Photo documentation of the axillary reconstruction using the posterior arm flap. a Marking of the wide excision including all hair-bearing skin in the right axilla. b Radical excision of the marked area and design of the posterior arm flap. c Complete flap

elevation with corresponding neurovascular pedicle. $\mathbf{d}$ Axillary defect covered with the posterior arm flap. e Postoperative result of the bilateral axillary reconstruction 3 months after surgery.
Fig. 3. Wound healing of the reconstructed axilla in patients treated with the posterior arm flap or VAC + STSG 3 months after the primary excision.

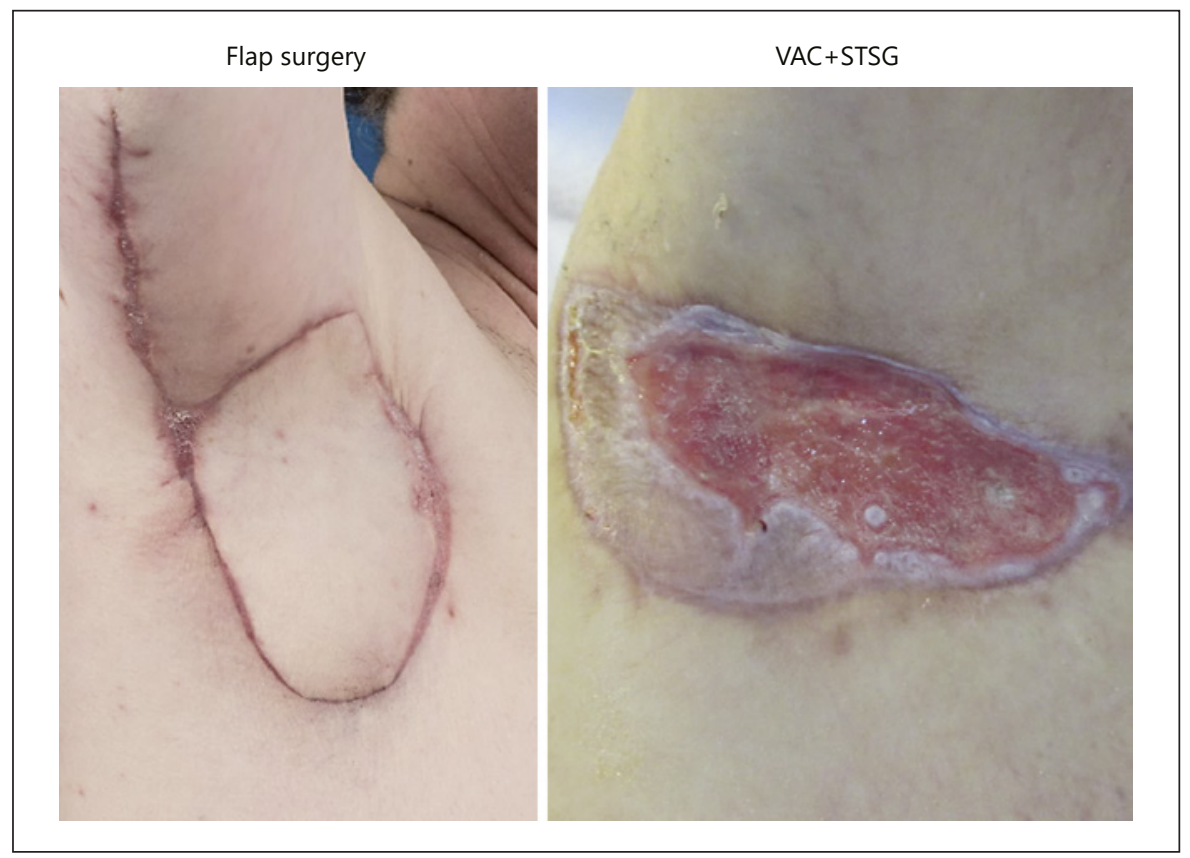


garding the reconstructive modalities secondary to radical resection [19]. The axilla is a complex trigonal, threedimensional space that harbors pliable soft tissue allowing unimpaired shoulder movements, lymphatic tissue as well as the brachial vessels and plexus nerves. The reconstructive approach after resection of HS should, therefore, account for an optimal soft-tissue support. Although wound conditioning with subsequent coverage using STSG remains a historically established approach for large defects, there are many indisputable drawbacks when used in the axillary region: unsafe graft take, poor scarring with reduced range of movement, prolonged recovery time, and multiple revision surgeries needed [18, $20,21]$. Due to these shortcomings, surgical reconstruction of the axilla using flap coverage has gained increased popularity [22]. Different flap options have been described in the literature for the coverage of the axilla: fasciocutaneous V-Y flaps, transposition flaps (e.g., Limberg flap), and musculocutaneous flaps (e.g., latissimus dorsi flap) [21, 23-25]. The posterior arm flap was introduced by Masquelet et al. [12] in 1985. Its usefulness for soft-tissue coverage of and around the axilla was successively proved [26-28]. Elliot et al. [29] used the posterior arm flap for patients suffering from burns or severe axillary HS with optimal postoperative outcomes. Besides its fairly straightforward dissection, recruiting redundant tissue from the upper arm with a relatively hidden donor site, the flap includes (parts of) the posterior cutaneous nerve of the arm, making a sensory recovery highly probable.

The present study focused on HS patients with axillary defects reconstructed by the posterior arm flap versus VAC + STSG. Interestingly, most patients in both groups were male, whereas the literature states that the predominant gender in HS is female [30]. This gender distribution in our study may be explained by the fact that males are more willing to undergo surgery with scars around the axilla and the upper arm as compared to females [31]. This notion, however, does not imply that gender may influence the surgical or clinical outcome of our study [32]. Our data demonstrated a longer mean operation time for the first surgical procedure in the flap group as opposed to the VAC + STSG group. However, the cumulative operation time did not differ between the groups. Nevertheless, the cumulative number of surgical procedures needed for complete wound closure was highest in the VAC + STSG group. This is explained by the necessary multiple regrafting surgeries as well as changes of VAC dressings after the primary excision. Similar results were reported by Chen and

Reconstruction of Axillary Defects after Excision of HS
Friedman [11], where 3 of 11 patients needed regrafting; only 8 of 24 defect sites showed skin graft take over $90 \%$, and isolated abscess formations were documented almost in all patients adjacent to the grafted areas. A prolonged operation time for axillary defect coverage using a pedicled flap compared to STSG coverage was reported in a study be Lee et al. [20] as well. Consequently, no need for regrafting or VAC dressing changes in the flap group resulted in the statistically significant decrease in the in-patient stay, number of out-patient claims, time to complete wound healing, as well as return to work.

Although a recent review by Fertitta et al. [33] pointed out high recurrence rates (56.4\%) in areas after one-stage surgical closure using flaps, our follow-up claims of up to 3 years after the primary resection showed no recurrence in the posterior arm flap group. By contrast, the only recurrences reported were found in patients treated with VAC + STSG. The high recurrence rate in the review by Feritta et al. [33] may be explained by an incomplete resection of the hair-bearing axillary area. Thus, the authors of the present article emphasize the absolute necessity of a radical resection approach, also including areas not actively affected by HS in the axilla.

Our data showed lowest scarring formation for group A. Scarring and contracture formation, in addition to pain, have been reported as the most frequent complications after defect coverage using STSG or secondary intention $[18,20]$. Notably, patients with burns affecting the axillary area suffer from devastating movement restrictions due to scar contractures [34]. None of the patients reconstructed with the posterior arm flap experienced functional impairment of the shoulder in contrast to almost half of the patients treated with VAC + STSG. One of the underestimated postoperative endpoints of defect coverage surgery is the sensory recovery of the reconstructed area. In our study, we demonstrated a superior sensory recovery in the flap group as compared to the VAC + STSG group using the Mackinnon-Dellon scale for sensory recovery [15]. Comparable data throughout the literature is lacking.

Healing by secondary intention (without skin grafting) of axillary defects has been discussed in previous work [18]. We, therefore, descriptively assessed 3 patients with 6 axillae treated by secondary intention. All patients $(n=3)$ were smokers and were diagnosed with Hurley stage II. The surgery in this subgroup demonstrated the shortest operation time of $17.0 \mathrm{~min}$ (IQR 15.0-30.0) encompassing only one primary excision, which resulted in an in-patient stay of 2.0 days (IQR 1.0- 
5.0). Nevertheless, the clinical outcome regarding scarring, sensory recovery, and time to complete wound healing was worse (VSS 9.0 [IQR 6.0-11.0], 1 [IQR 1-1], and 72.0 days [IQR 67.0-131.0], respectively). Poor clinical outcome with functional aesthetic deficits makes the healing by secondary intention an obsolete treatment approach.

Furthermore, data on cost analysis of the two reconstructive approaches is scarce [35]. Our cost analysis revealed an average saving of $25.3 \%$ in the flap group versus the VAC + STSG group for the entire axillary reconstruction treatment. After reimbursement, the average cost coverage was higher for the flap group than for the VAC + STSG group as well. These findings correspond with a study by Dobbs et al. [35], which showed cost savings of $19.7 \%$ in the keystone flap versus the STSG group for reconstruction of skin cancer defects in different body locations. The high cost expenditures for the VAC + STSG coverage of the axillary defects can be explained by longer hospitalization, multiple revision surgeries, and longer wound healing processes.

The present study has several potential limitations. Various comorbidities were not considered regarding the time of postoperative wound healing due to the retrospective study design.

\section{Conclusion}

Our findings suggest that axillary reconstruction by the neurovascular-pedicled posterior arm flap yields optimal functional and aesthetic results with less time to complete wound healing, less cumulative operations, and reduced in-hospital stay. It is, therefore, considered superior to wound conditioning with subsequent skin grafting.

\section{Key Message}

Axillary reconstruction by the posterior arm flap is superior to secondary healing with skin grafting.

\section{Statement of Ethics}

Approval was obtained from the Ethics Committee of Zurich (BASEC-No.: 2020-01135). Written informed consent was obtained from participants in terms of the general consent at the University Hospital Zurich (http://www.pathologie.usz.ch/fachwissen/labors-und-angebote/Documents/674637_Generalkonsent_ ENG_A3q.pdf).

\section{Conflict of Interest Statement}

The authors have no conflicts of interest to declare.

\section{Funding Sources}

This study received no specific grant from any funding agency in the public, commercial, or not-for-profit sectors.

\section{Author Contributions}

V.T., R.S., and H.J.K.: conception and design. R.S., M.W., B.S.K., and H.J.K.: surgical procedure. V.T. and H.J.K.: data acquisition and analysis. P.G. and H.J.K.: supervision. All authors: critical revision and final approval of the version to be published.

\section{Data Availability Statement}

All data needed to evaluate the conclusions in the paper are presented in the paper. Additional data related to this paper may be requested from the authors.

\section{References}

1 Jemec GB. Clinical practice. Hidradenitis suppurativa. N Engl J Med. 2012 Jan;366(2): $158-64$.

2 Sabat R, Jemec GBE, Matusiak Ł, Kimball AB, Prens E, Wolk K. Hidradenitis suppurativa. Nat Rev Dis Primers. 2020 Dec;6(1):18.

3 Menter A. Recognizing and managing comorbidities and complications in hidradenitis suppurativa. Semin Cutan Med Surg. 2014 Jun;33(3 Suppl l):S54-6.

4 Saunte DML, Jemec GBE. Hidradenitis suppurativa: advances in diagnosis and treatment. JAMA. 2017 Nov;318(20):2019-32.
5 Hendricks AJ, Hsiao JL, Lowes MA, Shi VY. A comparison of international management guidelines for hidradenitis suppurativa. Dermatology. 2019 Oct;1-16:1.

6 Kohorst JJ, Baum CL, Otley CC, Roenigk RK, Schenck LA, Pemberton JH, et al. Surgical management of hidradenitis suppurativa: outcomes of 590 consecutive patients. Dermatol Surg. 2016 Sep;42(9):1030-40.

7 Zouboulis CC, Desai N, Emtestam L, Hunger RE, Ioannides D, Juhász I, et al. European S1 guideline for the treatment of hidradenitis suppurativa/acne inversa. J Eur Acad Dermatol Venereol. 2015 Apr;29(4):619-44.
8 Zouboulis CC, Bechara FG, Dickinson-Blok JL, Gulliver W, Horváth B, Hughes R, et al. Hidradenitis suppurativa/acne inversa: a practical framework for treatment optimization - systematic review and recommendations from the HS ALLIANCE working group. J Eur Acad Dermatol Venereol. 2019 Jan;33(1):19-31.

9 Tanaka A, Hatoko M, Tada H, Kuwahara M, Mashiba K, Yurugi S. Experience with surgical treatment of hidradenitis suppurativa. Ann Plast Surg. 2001 Dec;47(6):636-42. 
10 Soldin MG, Tulley P, Kaplan H, Hudson DA, Grobbelaar AO. Chronic axillary hidradenitis - the efficacy of wide excision and flap coverage. Br J Plast Surg. 2000 Jul;53(5):434-6.

11 Chen E, Friedman HI. Management of regional hidradenitis suppurativa with vacuum-assisted closure and split thickness skin grafts. Ann Plast Surg. 2011 Oct;67(4):397401.

12 Masquelet AC, Rinaldi S, Mouchet A, Gilbert A. The posterior arm free flap. Plast Reconstr Surg. 1985 Dec;76(6):908-13.

13 Clavien PA, Barkun J, De Oliveira ML, Vauthey JN, Dindo D, Schulick RD, et al. The Clavien-Dindo classification of surgical complications: five-year experience. Ann Surg. 2009 Aug;250(2):187-96.

14 Sullivan T, Smith J, Kermode J, McIver E, Courtemanche DJ. Rating the burn scar. J Burn Care Rehabil. 1990 May;11(3):256-60.

15 Mackinnon SE, Dellon AL. Clinical nerve reconstruction with a bioabsorbable polyglycolic acid tube. Plast Reconstr Surg. 1990;85(3): 419-24.

16 Besson P. REKOLE: Betriebliches Rechnungswesen im Spital. 4th ed. Bern: H+ die Spitäler der Schweiz; 2016 [cited 2021 May 24]. Available from: https://books.google.at/ books/about/Rekole_betriebliches_Rechnungswesen_im_S.html?id=hgDsoQEACAAJ\& redir_esc $=y$.

17 Morteza Seyed Jafari S, Knüsel E, Cazzaniga S, Hunger RE. A retrospective cohort study on patients with hidradenitis suppurativa. Dermatology. 2018;234(1-2):71-8.

18 Posch C, Monshi B, Quint T, Vujic I, Lilgenau $\mathrm{N}$, Rappersberger K. The role of wide local excision for the treatment of severe hidradenitis suppurativa (Hurley grade III): Retrospective analysis of 74 patients. J Am Acad Dermatol. 2017;77(1):123-e5.
19 Orenstein LAV, Nguyen TV, Damiani G, Sayed C, Jemec GBE, Hamzavi I. Medical and surgical management of hidradenitis suppurativa: a review of international treatment guidelines and implementation in general dermatology practice. Dermatology. 2020; 236(5):393-412.

20 Lee JY, Chai SC, Mat Zain MA, Basiron N. A review of the reconstructive methods in the management of axillary hidradenitis suppurativa. Eur J Plast Surg. 2020;43(3):295-302.

21 Wormald JC, Balzano A, Clibbon JJ, Figus A. Surgical treatment of severe hidradenitis suppurativa of the axilla: Thoracodorsal artery perforator (TDAP) flap versus split skin graft. J Plast Reconstr Aesthet Surg. 2014 Aug; 67(8):1118-24.

22 Scuderi N, Monfrecola A, Dessy LA, Fabbrocini G, Megna M, Monfrecola G. Medical and surgical treatment of hidradenitis suppurativa: a review. Skin Appendage Disord. 2017 May;3(2):95-110.

23 Varkarakis G, Daniels J, Coker K, Oswald T, Akdemir O, Lineaweaver WC. Treatment of axillary hidradenitis with transposition flaps: A 6-year experience. Ann Plast Surg. 2010; 64(5):592-4.

24 Rehman N, Kannan RY, Hassan S, Hart NB. Thoracodorsal artery perforator (TAP) type I $\mathrm{V}$-Y advancement flap in axillary hidradenitis suppurativa. Br J Plast Surg. 2005;58(4):4414.

25 Angrigiani C, Grilli D, Siebert J. Latissimus dorsi musculocutaneous flap without muscle. Plast Reconstr Surg. 1995;96(7):1608-14.

26 Sirvan SS, Demir IA, Irmak F, Sevim KZ, Dagdelen D, Yazar SK, et al. Posterior arm perforator flap for axillary reconstruction after hidradenitis suppurativa excision. Plast Surg (Oakv). 2019 Aug;27(3):204-10.
27 Schmidt M, Dunst-Huemer KM, Lazzeri D, Schoeffl H, Huemer GM. The versatility of the islanded posterior arm flap for regional reconstruction around the axilla. J Plast Reconstr Aesthet Surg. 2015 Jul;68(7):953-9.

28 Guha G, Agarwal AK, Gupta S, Gupta S, Murmu MB, Chumbale P, et al. Posterior arm flap in management of axillary contracture. Burns. 2013;39(5):972-7.

29 Elliot D, Kangesu L, Bainbridge C, Venkataramakrishnan $\mathrm{V}$. Reconstruction of the axilla with a posterior arm fasciocutaneous flap. $\mathrm{Br}$ J Plast Surg. 1992;45(2):101-4.

30 Garg A, Kirby JS, Lavian J, Lin G, Strunk A. Sex- and age-adjusted population analysis of prevalence estimates for hidradenitis suppurativa in the United States. JAMA Dermatol. 2017;153(8):760-4.

31 Karlson EW, Daltroy LH, Liang MH, Eaton HE, Katz JN. Gender differences in patient preferences may underlie differential utilization of elective surgery. Am J Med. 1997 Jun; 102(6):524-30.

32 Aghdassi SJS, Schröder C, Gastmeier P. Gender-related risk factors for surgical site infections. Results from 10 years of surveillance in Germany. Antimicrob Resist Infect Control. 2019 Dec;8(1):95.

33 Fertitta L, Hotz C, Wolkenstein P, Méningaud JP, Sawan D, Hersant B, et al. Efficacy and satisfaction of surgical treatment for hidradenitis suppurativa. J Eur Acad Dermatol Venereol. 2020;34(4):839-45.

34 Ogawa R, Hyakusoku H, Murakami M, Koike S. Reconstruction of axillary scar contractures - retrospective study of 124 cases over 25 years. Br J Plast Surg. 2003;56(2):100-5.

35 Dobbs TD, Jovic TH, Jessop ZM, Kyle A, Hutchings HA, Whitaker IS. Objective and patient-reported assessments of skin grafts and keystone flaps - a pilot retrospective cohort study. Plast Reconstr Surg Glob Open. 2018;6(11):e2024-9. 